\title{
Identification of the Risk Factors Associated with Helicobacter pylori Infection in Lahore, Pakistan
}

\author{
Ashfaq Ali ${ }^{1}$, Muhammad Riaz Ahmad ${ }^{2}$, Zafar Iqbal ${ }^{3}$ and Abdul Basit ${ }^{4 *}$ \\ ${ }^{1}$ Department of Statistics, Govt. M.A.O. College, Lahore, Pakistan \\ ${ }^{2}$ Govt. Postgraduate College, Jaranwal, Pakistan \\ ${ }^{3}$ Department of Statistics, Govt. Post Graduate College, Gujranwala, Pakistan \\ ${ }^{4}$ State Bank of Pakistan, Karachi, Pakistan
}

\begin{abstract}
In this study, significant risk factors of Helicobacter pylori infection in Lahore are investigated through a case-control study by using descriptive and analytical approaches. A sample of 362 subjects was selected from the Gastroenterology Departments and OPDs of different hospitals of Lahore. About 25 risk factors with sub categories were included in the study. For bivariate analysis, the chi-square, phi/v statistics and Kendall's tau-b are used. From descriptive analysis, it was found that the persons who eat from restaurants have more risk of infection as compare to persons who eat homemade food. By the descriptive analysis, it was also observed that risk of Helicobacter pylori infection increases with an increase in the number of family members per house and in the number of persons living per room. Furthermore, similar results were observed in the bivariate analysis. In the analysis, the five risk factors including age, food eat, food liked, dental complains and number of persons living per room are found to be positively significant having the odds ratios and $95 \%$ confidence intervals of odds ratios $(1.025 ; 1.003-1.047),(9.596 ; 4.767-19.314),(3.500 ; 1.509-8.119),(3.204$ $1.685-6.094)$ and $(2.772 ; 1.496-5.139)$, respectively. While the three risk factors including usage of tea, educational leve and sewerage system are found to be negatively significant having odds ratios and $95 \%$ confidence intervals for the odds ratios $(0.221 ; 0.119-0.411),(0.216 ; 0.115-0.404)$ and $(0.401 ; 0.218-0.738)$, respectively, which indicates that these three risk factors are protective factors against Helicobacter pylori infection. According to this study, the subjects who eat from restaurants have higher risk of Helicobacter pylori infection as compared to all other risk factors.
\end{abstract}

Keywords: Helicobacter pylori infection; Risk factors; Logistic regression; Odds ratio; Controls; Significance; Retrospective

\section{Introduction}

During infections due to bacteria, factors related with bacteria, host and environment, all three are cause of infection results and infection appearance. For the development of a stubborn infection, the bacteria basically have the ability of adapting to a number of different ecological variations that happen during the infection. An example of the bacterium is the Helicobacter pylori (H. pylori) which is the cause of the stubborn infections in the stomach of human.

H. pylori infect more than $30 \%$ population of the world and in few countries this infects above than $50 \%$ people from the total population [1]. H. pylori is one of the most common bacterial infections in human beings. In 1994, Helicobacter pylori was categorized as a class I human carcinogen by the WHO International Agency for Research on Cancer (IARC) due to its epidemiological connection to gastric cancer.

In Pakistan, acid peptic disease due to the prevalence of Helicobacter pylori Bacterium infection is very high among population and the numbers of patients are continuously increasing mainly due to non-availability of ideal diagnostic and treatment facilities in public sector healthcare services. As $H$. pylori is a rising issue in Pakistan so according to experts of health $H$. pylori infection may become chronic with the chances of gastric carcinoma and stomach cancer, if it is not treated fully and properly [2].

\section{Material and Methods}

This study is hospital-based, an epidemiological and analytical case and control which is conducted to find out the risk factors of the Helicobacter pylori infection in patients of all age groups. For case group, the patients from the Gastroenterology Departments and Outdoor Patient Departments (OPD) of different hospitals of Lahore, was the target population while the attendants of the patients or all the other patients having any kind of stomach disease other than $H$. pylori infection who came to the above mentioned departments was the target population for the control group.

This study consists of 362 respondents including 181 cases and 181 controls. There are almost 25 risk factors including age, gender, marital status, smoking, quantity of cigarettes smoked on each day, usage of tea, quantity of cups of tea taken on each day, usage of coffee, quantity of cups of coffee taken on each day, food's type to eat, type of food to like, source of drinking water, dental complains, educational level, socioeconomic level, garbage collection system, type of accommodation, number of rooms in accommodation, number of persons per room, evaluation of sewerage system, use of drugs, use of antibiotics, contacts with animals and travelling outside the native district.

From above factors seven are treated as quantitative including age, quantity of cigarettes smoked on each day, quantity of cups of tea taken on each day, quantity of cups of coffee taken on each day, income, number of rooms in accommodation, number of persons per room. All the other variables are qualitative from which most of the variables are in dichotomous form. To present the complete and comprehensive

*Corresponding author: Abdul Basit, State Bank of Pakistan, Karachi, Pakistan, Tel: 0092-333-4859346; E-mail: basit_ravian917@hotmail.com

Received January 03, 2017; Accepted May 27, 2017; Published May 31, 2017

Citation: Ali A, Ahmad MR, Iqbal Z, Basit A (2017) Identification of the Risk Factors Associated with Helicobacter pylori Infection in Lahore, Pakistan. J Biom Biostat 8 348. doi: 10.4172/2155-6180.1000348

Copyright: () 2017 Ali A, et al. This is an open-access article distributed under the terms of the Creative Commons Attribution License, which permits unrestricted use, distribution, and reproduction in any medium, provided the original author and source are credited. 
analysis, this part of study is divided into two parts; analytical and model building.

In this study, response variable is binary and independent variables are both categorical and continuous. Also in this situation, there exists nonlinear relationship between response variable and independent variables, so the best and most appropriate choice for modelling is the binary logistic regression model in order to predict the occurrence of H. pylori infection [3].

\section{Results}

The sample consists of 181 (50.0\%) cases and 181 (50.0\%) controls. The age was treated as continuous variable. The minimum and maximum ages of the subjects were 15 years and 80 years, respectively. The average age of patients was $39.89 \pm 13.972$ years.

Association analysis shows that the risk factors, smoking, number of cigarettes smoked per day, type of food, type of liked food, dental complains, number of family members per house and number of persons living per room are found to be positively significantly associated with Helicobacter pylori infection, while the risk factors use of tea, source of drinking water, educational level, socio economic status, garbage collection system and sewerage system are found to be negatively associated with Helicobacter pylori infection [4-9]. On the other hand, Gender, marital status, use of antibiotics in last month, contact with animals and travelled outside the native city/town have not significant association infection. The value of $\mathrm{V} / \mathrm{Phi}$ statistic for the type of food is 0.421 , which is the highest value, so it is highly associated nominal categorical variable with Helicobacter pylori infection among all the significant nominal risk factors [10-15]. The value of Kendall's Tau-b statistic for the number of persons living per room is 0.338 , which is the highest value, so it is highly associated ordinal categorical variable with Helicobacter pylori infection among all the significant ordinal risk factors.

Binary logistic regression model is fitted. In this model, regression coefficients, odds ratios, $\mathrm{p}$-values and $95 \%$ confidence intervals of odds ratios are calculated for patients. Omnibus and Hosmer-Lemeshow tests are used to check the overall appropriateness of the model (Table 1).

It is examined that model is significant, because in Omnibus test the value of $\mathrm{p}=0.000$ is less than the level of significance 0.05 (5\%) for model, so at least one of the predictors is playing a significant role in predicting the response variable and the fitted model is adequate [16-20]. In Hosmer-Lemeshow test, the value of $p=.996$, so HosmerLemeshow test is insignificant, which shows that the fitted model is adequate.

For checking the overall goodness of fit of the model, Cox \& Snell and Nagelkerke $\mathrm{R}^{2}$ are used for model.

The values of Cox \& Snell and Nagelkerke $\mathrm{R}^{2}$ for male model are 0.464 and 0.618 , respectively, which shows that strength of association is high between the response and independent [21].

From Table 2, it is examined that 147 (81.2\%) uninfected (controls) and $153(84.5 \%)$ infected (cases) are rightly predicted, while 28 (15.5\%) infected (cases) and 34 (18.8\%) uninfected (controls) are misclassified $28(15.5 \%)$ as uninfected (controls) and 34 (18.8\%) as infected (cases). On the whole, the numbers (percentages) of rightly classified and misclassified respondents are $300(82.9 \%)$ and 62 (17.1\%), respectively. The value of accurate classification is sufficiently high, so the fitted model is satisfactory.
From Omnibus test, Hosmer-Lemeshow test and correct classification, it is examined that the logistic regression model satisfactorily fit the data, so the $95 \%$ CI are furthermore applicable for inferences.

From Table 3, eight risk factors consisting of Age, Tea, Food eat (FE), Food liked (FL), Dental complains (DC), Educational level (Edu.), Number of persons living per room (NPPR) and Sewerage system (SS) are significant.

$$
\begin{aligned}
& \text { The fitted logit model is given as; } \\
& \ln \left[\frac{\pi(x)}{1+\pi(x)}\right]=Z=-1.694+0.024(\text { Age })-1.509(\text { Tea })+ \\
& 2.261(\mathrm{FE})+1.253(\mathrm{FL})+1.164(\mathrm{DC})-1.534(\mathrm{Edu} .)+1.020(\mathrm{NPPR})-0.913(\mathrm{SS})
\end{aligned}
$$

It is observed that the five factors including Age, Food eat, Food liked, Dental complain and number of person living per room are positively significant, which means that $H$. pylori infection and these risk factors are directly related and the three factors including Tea, Educational level and Sewerage System are observed to be negatively significant which means that the H. pylori $[22,23]$ infection and these risk factors are inversely related.

Explanation for the model coefficients, odds ratios and its $95 \%$ confidence intervals are discussed here.

As the value of odds ratio for the risk factor age is 1.025 , which investigated that the subjects with the older age have about 1.025 times more risk of Helicobacter pylori infection than the subjects with young age [24-26]. From this study, it is examined that the effect of age is directly associated with the Helicobacter pylori infection, because in the model the value of logit coefficient is 0.024 with $\mathrm{p}=0.028$. The $95 \%$ confidence interval for odds ratio of the age is $(1.003,1.047)$, which indicates that age has significant association with $H$. pylori infection, because confidence interval does not contain the value of one.

In this study, it is examined that the effect of tea is inversely associated with the Helicobacter pylori infection. As the value of odds ratio for tea in the model is 0.221 , which explained that the subjects who take tea have $(1-0.221=0.779) 77.9 \%$ protection against infection as compared to subjects who do not take tea. The $95 \%$ confidence interval for odds ratio of the tea is $(0.119,0.411)$, which indicates that tea has significant association with $H$. pylori infection, because confidence interval does not contain the value of one.

In this study, subjects were divided into two categories, one who eat homemade food and second who eat from restaurants and examined that the effect of food is directly associated with the Helicobacter pylori infection. Because the value of odds ratio for food in the model is 9.596, so the subjects who eat from restaurants have risk of infection 9.596 times more than the subjects who eat homemade food. The $95 \% \mathrm{CI}$ for OR of the food is $(4.767,19.314)$, which indicates that food has significant association with $H$. pylori infection, because confidence interval does not contain the value of one.

As the value of odds ratio for types of liked foods is 3.500, which investigated that the subjects who liked spicy food have about 3.500 times more risk of Helicobacter pylori infection than the subjects who liked less spicy food. From this study, it is also examined that the effect of types of liked foods is directly associated with the Helicobacter pylori infection, because the value of logit coefficient is 1.253 with $\mathrm{p}=0.004$. The $95 \%$ confidence interval for odds ratio of the types of liked foods is $(1.509,8.119)$, which indicates that types of liked foods have significant 
Citation: Ali A, Ahmad MR, Iqbal Z, Basit A (2017) Identification of the Risk Factors Associated with Helicobacter pylori Infection in Lahore, Pakistan. J Biom Biostat 8: 348. doi: 10.4172/2155-6180.1000348

Page 3 of 5

\begin{tabular}{|c|c|c|c|c|c|c|c|}
\hline \multirow[t]{3}{*}{ Variables } & \multirow[t]{3}{*}{ Classification } & \multicolumn{4}{|c|}{ H. pylori infection } & \multirow{2}{*}{\multicolumn{2}{|c|}{ Total }} \\
\hline & & \multicolumn{2}{|c|}{ No } & \multicolumn{2}{|c|}{ Yes } & & \\
\hline & & No. & \%age & No. & $\%$ age & No. & \%age \\
\hline \multirow[t]{2}{*}{ Gender } & Female & 65 & 48.9 & 68 & 51.1 & 133 & 36.7 \\
\hline & Male & 116 & 50.7 & 113 & 49.3 & 229 & 63.4 \\
\hline \multirow[t]{2}{*}{ Marital Status } & Unmarried & 67 & 51.9 & 62 & 48.1 & 129 & 35.6 \\
\hline & Married & 114 & 48.9 & 119 & 51.1 & 233 & 64.4 \\
\hline \multirow[t]{2}{*}{ Smoking } & No & 155 & 54.6 & 129 & 45.4 & 284 & 78.5 \\
\hline & Yes & 26 & 33.3 & 52 & 66.7 & 78 & 21.5 \\
\hline \multirow[t]{4}{*}{ No. of cigarettes smoked per day } & 0 & 155 & 54.6 & 129 & 45.4 & 284 & 78.5 \\
\hline & $1-10$ & 18 & 34.0 & 35 & 66.0 & 53 & 14.6 \\
\hline & $11-20$ & 6 & 26.1 & 17 & 73.9 & 23 & 6.4 \\
\hline & Above 20 & 2 & 100 & 0 & 0 & 2 & 0.6 \\
\hline \multirow[t]{2}{*}{ Use of tea } & No & 52 & 31.7 & 112 & 68.3 & 164 & 45.3 \\
\hline & Yes & 129 & 65.2 & 69 & 34.8 & 198 & 54.7 \\
\hline \multirow[t]{2}{*}{ Use of coffee } & No & 181 & 50 & 181 & 50 & 362 & 100 \\
\hline & Yes & 0 & 0 & 0 & 0 & 0 & 0 \\
\hline \multirow[t]{2}{*}{ Type of food } & Homemade & 153 & 65.7 & 80 & 34.3 & 233 & 64.4 \\
\hline & Restaurant & 28 & 21.7 & 101 & 78.3 & 129 & 35.6 \\
\hline \multirow[t]{3}{*}{ Food liked } & Less spicy & 59 & 76.6 & 18 & 23.4 & 77 & 21.3 \\
\hline & Spicy & 95 & 47.5 & 105 & 52.5 & 200 & 55.2 \\
\hline & Over spicy & 27 & 31.8 & 58 & 68.2 & 85 & 23.5 \\
\hline \multirow[t]{2}{*}{ Source of drinking water } & Municipality/water pump & 98 & 38.4 & 157 & 61.6 & 255 & 70.4 \\
\hline & Filtered & 83 & 77.6 & 24 & 22.4 & 107 & 29.6 \\
\hline \multirow[t]{2}{*}{ Dental complains } & No & 142 & 64.0 & 80 & 36.0 & 222 & 61.3 \\
\hline & Yes & 39 & 27.9 & 101 & 72.1 & 140 & 38.7 \\
\hline \multirow[t]{2}{*}{ Educational Level } & Low & 53 & 30.1 & 123 & 69.9 & 176 & 48.6 \\
\hline & High & 128 & 68.8 & 58 & 31.2 & 186 & 51.4 \\
\hline \multirow[t]{3}{*}{ Socio economic status } & Below 20000 & 60 & 41.1 & 86 & 58.9 & 146 & 40.3 \\
\hline & $20000-40000$ & 72 & 51.4 & 68 & 48.6 & 140 & 38.7 \\
\hline & Above 40000 & 49 & 64.5 & 27 & 35.5 & 76 & 21.0 \\
\hline \multirow[t]{2}{*}{ Garbage collection system } & No & 81 & 44.5 & 101 & 55.5 & 182 & 50.3 \\
\hline & Yes & 100 & 55.6 & 80 & 44.4 & 180 & 49.7 \\
\hline \multirow[t]{2}{*}{ No. of family members per house } & $\leq 5$ & 82 & 70.1 & 35 & 29.9 & 117 & 32.3 \\
\hline & $>5$ & 99 & 40.4 & 146 & 59.6 & 245 & 67.7 \\
\hline \multirow[t]{2}{*}{ No. of persons living per room } & $\leq 3$ & 129 & 65.5 & 68 & 34.5 & 197 & 54.4 \\
\hline & $>3$ & 52 & 31.5 & 113 & 68.5 & 165 & 45.6 \\
\hline Evaluation of sewerage system & Poor & 16 & 16.8 & 79 & 83.2 & 95 & 26.2 \\
\hline & Good & 89 & 54.9 & 73 & 45.1 & 162 & 44.8 \\
\hline & Excellent & 76 & 72.4 & 29 & 27.6 & 105 & 29.0 \\
\hline Use of drugs & No & 178 & 49.7 & 180 & 50.2 & 358 & 98.9 \\
\hline & Yes & 3 & 75.0 & 1 & 25.0 & 4 & 1.1 \\
\hline Use of antibiotics in last month & No & 97 & 51.1 & 93 & 48.9 & 190 & 52.5 \\
\hline & Yes & 84 & 48.8 & 88 & 51.2 & 172 & 47.5 \\
\hline Contacts with animal & No & 113 & 48.3 & 121 & 51.7 & 234 & 64.6 \\
\hline & Yes & 68 & 53.1 & 60 & 46.9 & 128 & 35.4 \\
\hline Travelled outside native city/district & No & 50 & 56.2 & 39 & 43.8 & 89 & 24.6 \\
\hline & Yes & 131 & 48.0 & 142 & 52.0 & 273 & 75.4 \\
\hline
\end{tabular}

Table 1: Counts and percentages of cases and controls according to different risk factors.

\begin{tabular}{|c|c|c|c|c|}
\hline \multirow{2}{*}{ Observed } & \multicolumn{2}{|c|}{ Predicted } & Percentage \\
correct
\end{tabular}

Table 2: Correct and incorrect classification for the model.

association with $H$. pylori infection, because confidence interval does not contain the value of one.

As the value of odds ratio for the dental complains is 3.204 , which stated that the subjects who have dental diseases have risk of Helicobacter pylori infection 3.204 times more than the subjects who have not dental diseases. The $95 \%$ CI for OR of dental complain is $(1.685,6.094)$, which indicates that dental complain has significant association with $H$. pylori infection, because confidence interval does not contain the value of one.

The educational level was categorized as low and high. The educational level is examined as significant, because the values of odds ratio and its $95 \%$ confidence interval are 0.216 and $(0.115$, $0.404)$, respectively. The respondents with high education have (1 - $0.216=0.784) 78.4 \%$ protection against the subjects who have low 


\begin{tabular}{|c|c|c|c|c|c|c|c|c|}
\hline \multirow[t]{2}{*}{ FACTORS } & \multirow[t]{2}{*}{ B } & \multirow[t]{2}{*}{ S.E. } & \multirow[t]{2}{*}{ Wald } & \multirow[t]{2}{*}{ d.f. } & \multirow[t]{2}{*}{ Sig. } & \multirow[t]{2}{*}{$\operatorname{Exp}(B)$} & \multicolumn{2}{|c|}{$95 \% \mathrm{Cl}$ for $\operatorname{Exp}(\mathrm{B})$} \\
\hline & & & & & & & Lower & Upper \\
\hline Age & 0.024 & 0.011 & 4.837 & 1 & .028 & 1.025 & 1.003 & 1.047 \\
\hline Tea & -1.509 & 0.317 & 22.722 & 1 & .000 & 0.221 & 0.119 & 0.411 \\
\hline Food eat & 2.261 & 0.357 & 40.143 & 1 & .000 & 9.596 & 4.767 & 19.314 \\
\hline Food liked & 1.253 & 0.429 & 8.519 & 1 & .004 & 3.500 & 1.509 & 8.119 \\
\hline Dental comp. & 1.164 & 0.328 & 12.600 & 1 & .000 & 3.204 & 1.685 & 6.094 \\
\hline Edu. level & -1.534 & 0.320 & 22.921 & 1 & .000 & 0.216 & 0.115 & 0.404 \\
\hline NPPR & 1.020 & 0.315 & 10.489 & 1 & .001 & 2.772 & 1.496 & 5.139 \\
\hline Sewerage sys. & -0.913 & 0.311 & 8.618 & 1 & .003 & 0.401 & 0.218 & 0.738 \\
\hline Constant & -1.694 & 0.661 & 6.566 & 1 & .010 & 0.184 & & \\
\hline
\end{tabular}

Table 3: Model coefficients, P-values, OR and 95\% C.I. for OR.

\begin{tabular}{|c|c|c|c|c|c|c|c|c|c|c|}
\hline \multirow[t]{2}{*}{ SN } & \multicolumn{8}{|c|}{ Risk Factors } & \multirow[t]{2}{*}{$\mathbf{Z}$} & \multirow{2}{*}{$\hat{\pi}(x)$} \\
\hline & Age & Tea & FE & FL & DC & Edu. & NPPR & S.S. & & \\
\hline 1 & 50 & No & Rest. & Spicy & Yes & Low & 6 & Poor & 13.818 & 0.999999 \\
\hline 2 & 30 & No & Rest. & Spicy & Yes & Low & 6 & Poor & 13.338 & 0.999998 \\
\hline 3 & 20 & No & Rest. & Spicy & Yes & Low & 6 & Poor & 13.098 & 0.999998 \\
\hline 4 & 50 & No & Rest. & Spicy & Yes & Low & 5 & Poor & 12.798 & 0.999997 \\
\hline 5 & 50 & No & Rest. & Spicy & Yes & Low & 4 & Poor & 11.778 & 0.999992 \\
\hline 6 & 50 & Yes & Rest. & Spicy & Yes & Low & 6 & Poor & 12.309 & 0.999995 \\
\hline 7 & 50 & No & H.M & Spicy & Yes & Low & 6 & Poor & 11.557 & 0.999990 \\
\hline 8 & 50 & No & H.M. & Spicy & Yes & Low & 3 & Poor & 8.497 & 0.999796 \\
\hline 9 & 50 & No & Rest. & L.S & Yes & Low & 6 & Poor & 12.565 & 0.999996 \\
\hline 10 & 50 & No & Rest. & Spicy & No & Low & 2 & Poor & 8.574 & 0.999811 \\
\hline 11 & 50 & No & Rest. & Spicy & Yes & High & 6 & Poor & 12.284 & 0.999995 \\
\hline 12 & 50 & No & Rest. & Spicy & Yes & Low & 2 & Poor & 9.738 & 0.999941 \\
\hline 13 & 50 & No & Rest. & Spicy & Yes & Low & 6 & Good & 12.905 & 0.999997 \\
\hline 14 & 20 & Yes & H.M & L.S. & No & High & 2 & Good & 0.384 & 0.594837 \\
\hline
\end{tabular}

Table 4: Predicted probabilities

education. The $95 \%$ confidence interval for odds ratios for education is $(0.115,0.404)$, which indicate that educational level has significant association with $H$. pylori infection, because confidence interval does not contain the value of one. From this study it is examined that the effect of educational level is inversely associated with the Helicobacter pylori infection because the value of logit coefficient is -1.534 with $p=0.000$.

The number of persons per room was distributed into two mutually exclusive groups as 3 or less persons per room and above 3 persons per room and examined that the effect of number of persons per room is directly associated with the Helicobacter pylori infection, because value of logit coefficient is 1.020 with $\mathrm{p}=0.001$. Because the value of odds ratio for the number of person living per room in the model is 2.772 , so the subjects who live more than 3 persons per room have 2.772 times more risk of Helicobacter pylori infection as compared to subjects who live 3 or less persons per room [27-30]. The 95\% confidence interval for odds ratio of the number of persons per room is $(1.496,5.139)$, which indicates that number of persons per room has significant association with the $H$. pylori infection, because confidence interval does not contain the value of one.

From this study, it is examined that the effect of sewerage system is inversely associated with the Helicobacter pylori infection, because value of the logit coefficient is -0.913 with $p=0.003$. As the value of odds ratio for sewerage system in the model is 0.401 , which explain that the subjects with good sewerage system have $(1-0.401=0.599)$ $59.9 \%$ protection against infection as compared to subjects who have poor sewerage system in their houses. For sewerage system, the $95 \%$ confidence interval for odds ratio is $(0.218,0.738)$, which indicate that sewerage system has significant association with $H$. pylori infection, because confidence interval does not contain the value of one.

\section{Predicted probabilities}

Because eight risk factors are involved as predictors in the above fitted logistic regression equation, so there may exists numerous combinations of these risk factors.

As shown in serial no. 1 of Table 4, when all the significant risk factors associated with Helicobacter pylori infection are present that is subjects have older age with age 50 years, do not take tea, eat food from restaurants, liked spicy food, have dental complain, have low educational level, live 6 persons per room and have poor sewerage system, then these subjects have predicted probability of the occurrence of infection is 0.999999 , which means that subjects with the above mentioned risk factors have $99.9999 \%$ chance of the occurrence of infection. As shown in serial no. 2 of Table 4, when all the significant risk factors associated with Helicobacter pylori infection are present except subjects age is 30 years means that subjects are not of old age, then these subjects have the predicted probability of the occurrence of infection is 0.999998 .

As shown in serial no. 3 of Table 4, when all the significant risk factors associated with Helicobacter pylori infection are present except subjects age is now 20 years, which means that subjects are too young, then these subjects have the predicted probability of the occurrence of infection is 0.999998 .

Similarly to observe the influence of some of the individual risk factor, the predicted probabilities are calculated in Table 4, which are shown in serial no. 4 to 13 .

Finally as shown in serial no. 14 of Table 4 , when all the significant risk factors associated with Helicobacter pylori infection are absent 
Citation: Ali A, Ahmad MR, Iqbal Z, Basit A (2017) Identification of the Risk Factors Associated with Helicobacter pylori Infection in Lahore, Pakistan J Biom Biostat 8: 348. doi: 10.4172/2155-6180.1000348

that is subjects are of young age with age 20 years, take tea, eat food from homes, liked less spicy food, have not dental complain, have high educational level, live 2 persons per room and have good sewerage system, then these subjects have predicted probability of the occurrence of infection is 0.594837 , which is low to others.

\section{Conclusion}

The risk factors of Helicobacter pylori infection are thoroughly analyzed. Bivariate analysis revealed that the type of food is highly associated nominal categorical variable with Helicobacter pylori infection among all the significant nominal risk factors, because it has the highest value of $\mathrm{V} / \mathrm{Phi}$ statistic and the number of persons living per room is highly associated ordinal categorical variable with Helicobacter pylori infection among all the significant ordinal risk factors, because it has highest value of Kendall's Tau-b statistic.

In Bivariate Logistic regression analysis, we found that the risk factors food eat, food liked, dental complain and number of persons living per room are the most significant risk factors in developing Helicobacter pylori infection in subjects.

\section{References}

1. Salih BA (2009) Helicobacter pylori Infection in Developing Countries. Saudi J Gastroenterol 3: 201-207.

2. Rasheed F, Ahmad T, Bilal R (2011) Frequency of Helicobacter pylori infection using 13C-UBT in asymptomatic individuals of Barakaho, Islamabad, Pakistan. Journal of the College of Physicians and Surgeons Pakistan 6: 379-381.

3. Hosmer DW, Lemeshow S (2000) Applied Logistic Regression. ( $2^{\text {nd }}$ edn.), John Willey and Sons INC, USA.

4. Agresti A (2007) An introduction to categorical data analysis. ( $2^{\text {nd }}$ edn.), John Willey and Sons INC, USA.

5. Abu-Mugesieb MR (2007) Risk Factors Associated with Helicobacter pylor Infection in Gaza. Palestin.

6. Bali D, Rosamma J, Bali A (2010) The Association of Dental Plaque and Helicobacter Pylori Infection in Dyspeptic Patients undergoing Endoscopy. Journal of Clinical and Diagnostic Research 4: 3614-3621.

7. Bang VN, Nguyen GK, Phung DC, Okrainec K, Raymond J, et al. (2006) Intrafamilial Transmission of Helicobacter pylori Infection in Children of Households with Multiple Generations in Vietnam. Eur J Epidemiol: 459-463.

8. Basso L, Beattie S, Lawlor S, Clune J, Morain C (1994) A descriptive follow-up study on Helicobacter pylori infection before and after exposition to a war area. Eur J Epidemiol: 109-111.

9. Brenner H, Berg G, Lappus N, Kliebsch U, Bode G (1999) Alcohol Consumption and Helicobacter pylori Infection: Results from the German National Health and Nutrition Survey. Epidemiology.

10. Brenner H, Rochenbacher D, Bode G, Gommel R, Berg G, et al. (1998) Parental Smoking and Infection with Helicobacter pylori among Preschool Children in Southern Germany. Epidemiology.

11. Dominici P, Bellentani S, Rita A, Saccoccio G, Rose A, et al. (1999) Familia clustering of Helicobacter pylori infection: population based study. BMJ.

12. Epplein M, Abraham MY, Laurence NK (2008) Association of Helicobacte pylori infection and diet on the risk of gastric cancer: a case-control study in Hawaii. Cancer Causes Control 8: 869-877.

13. Etukudo OM, Ikpeme EE, Ekanem EE (2012) Seroepidemiology of Helicobacter pylori infection among children seen in a tertiary hospital in Uyo, southern Nigeria. Pan African Medical Journal.

14. Forman D, Newell DG, Fullerton F, Yarnell J, Stacey AR, et al. (1991) Association between infection with Helicobacter pylori and risk of gastric cancer: evidence from a prospective investigation. BMJ.

15. Goodwin CS, Armstrong JA, Chilvers T (1989) Transfer of Campylobacter Pylori and Campylobacter mustelae to Helicobacter gen. nov. as Helicobacter Pylori Comb. nov. and Helicobacter mustelae comb. nov. respectively. Int. J. Syst Bacteriol, 39, 397-405.
16. Guo Z, Li Y, Xu Z, Ji F, Wang L, et al. (2002) A case-control study on risk factors of helicobacter pylori infection in out-patients with stomach diseases. Zhonghua Yu Fang Yi Xue Za Zhi: 187-190.

17. Hessey SJ, Spencer J, Wyatt JI, Sobala G, Rathbone BJ, et al. (1990) Bacterial adhesion and disease activity in Helicobacter associated chronic gastritis. GUT 2: 134-138.

18. Jennifer M, Sue JG, Ezzati M (2009) Effects of Helicobacter pylori infection and smoking on gastric cancer incidence in China: a population-level analysis of trends and projections. Cancer Causes Control 10: 2021-2029.

19. Lyra AC, Santana G, Santana N, SilBangy-Neto A, Magalhães E, et al. (2003) Seroprevalence and risk factors associated with Helicobacter pylori infection in blood donors in Salvador, Northeast-Brazil. Braz J Infect Dis.

20. Marshall BJ, Armstrong JA, McGechie DB, Glancy RJ (1985) Attempt to fulfil Koch's postulates for Pylori Campylobacter. Med J Aust 142: 436-439.

21. Mhaskar RS (2010) Epidemiological Study of Contributing Factors in the Development of Peptic Ulcer and Gastric Cancer Initiated by Helicobacter Pylori Infection in India.

22. Moayyedi P, Forman D, Duffett S, Mason S, Brown J, et al. (2005) Association between Helicobacter pylori infection and adult height. European Journal of Epidemiology 5: 455-465.

23. Muhsen K, Ornoy A, Akawi A, Alpert G Cohen D (2011) An association between Helicobacter pylori infection and cognitive function in children at early schoo age: a community-based study. BMC Pediatrics.

24. Patel P, Mendal MA, Khulusi S, Northfield TC, Strachan DP (1994) Helicobacter pylori infection in childhood: risk factors and effect on growth. BMJ.

25. Perri F, Pastore M, Leandro G, Clemente, R, Ghoos Y, et al. (1997) Helicobacte pylori infection and growth delay in older children. Archives of Disease in Childhood: 46-49.

26. Pfefferle PI, Kramer A (2008) Helicobacter pylori-infection status and childhood living conditions are associated with signs of allergic diseases in an occupational population. Eur J Epidemiol: 635-640.

27. Rothenbacher D, Brenner H, Bode G, Adler G (2000) Does Materna Smoking Hinder Mother-Child Transmission of Helicobactor Pylori infection? Epidemiology.

28. Razzaq A, Iqbal Z, Raffad Saeed M, Siddiq M (2011) Frequency of Helicobacte Pylori infection. Professional Med J 4: 693-96.

29. The EUROGAST Study Group (1993) Epidemiology of, and risk factors for, Helicobacter pylori infection among 3194 asymptomatic subjects in 17 populations. Gut 1672-1676.

30. YEE Y, Koo MW, Szeto M (2002) Chinese tea consumption and lower risk of Helicobacter infection. Journal of Gastroenterology and Hepatology: 552-555. 